The University of Maine

\title{
DigitalCommons@UMaine
}

Anthropology Faculty Scholarship

Anthropology

$1-2010$

\section{Fingering a Murderer: A Successful Anthropological and Radiological Collaboration}

B. G. Brogdon

Marcella H. Sorg

University of Maine, mhsorg@maine.edu

Kerriann Marden

Follow this and additional works at: https://digitalcommons.library.umaine.edu/ant_facpub

Part of the Biological and Physical Anthropology Commons, and the Radiology Commons

\section{Repository Citation}

Brogdon, B. G.; Sorg, Marcella H.; and Marden, Kerriann, "Fingering a Murderer: A Successful Anthropological and Radiological Collaboration" (2010). Anthropology Faculty Scholarship. 29.

https://digitalcommons.library.umaine.edu/ant_facpub/29 


\title{
Fingering a Murderer: A Successful Anthropological and Radiological Collaboration*
}

\begin{abstract}
We illustrate an interdisciplinary approach to identify a victim in a case with complex taphonomic and procedural issues. Burning, fragmentation, species commingling, and examination by multiple experts required anthropological preparation and analysis combined with radiographic adaptations to image and match trabecular patterns in unusually small, burned specimens. A missing person was last seen in the company of a reclusive female on a remote rural property. A warranted search found several burn sites containing human and animal bones. Fragment preparation, analysis, and development of a biological profile by anthropologists enabled examination by the odontologist, molecular biologist, and radiologist, and justified use of antemortem radiographs from one potential victim. Visual and radiological comparison resulted in a positive (later confirmed) identification of the victim by radiological matches of three carpal phalanges. Although some dimensional changes are expected with burning, morphological details were preserved, aided by selection of relatively intact, small bones for comparison.
\end{abstract}

KEYWORDS: forensic science, radiology, forensic anthropology, identification, homicide, burned remains, taphonomy

A young man reported missing by his mother was last seen on a rural "horse farm" in New Hampshire in the company of the somewhat reclusive female owner. She had a history of multiple tumultuous relationships and a previous assault charge. A warrant was obtained to search the property. Burned bones, a burned mattress, a burn-barrel, and other burn sites were eventually discovered. Excavation and collection at these sites yielded 30 five-gallon buckets full of burned material. After initial screening coordinated by personnel with the New Hampshire Office of Chief Medical Examiner, several hundred burned bone fragments and other artifacts, including all available antemortem radiographs of the presumed decedent, were sent to their consulting forensic anthropology team in Maine for analysis.

\section{Materials and Methods}

The initial examination of the remains was performed by the forensic anthropology team. Several hundred hours were consumed by the daunting analysis of separating and photographing human bone and tooth fragments commingled with those of at least eight non-human species: bird, turtle, deer, cow, fish, rabbit, rodent, and horse. There was evidence that there had been intentional mixing and scattering of remains between the several burn sites; in several

${ }^{1}$ Department of Radiology, University of South Alabama Medical Center, 2451 Fillingim St., Mobile, AL 36617.

${ }^{2}$ Department of Anthropology and Margaret Chase Smith Policy Center, University of Maine, Orono, ME 04469.

${ }^{3}$ Doctoral Candidate, Department of Anthropology, Tulane University, 1326 Audubon St., New Orleans, LA 70118.

*Presented in part at the 61st Annual Meeting of the American Academy of Forensic Sciences in Denver, CO, February 16-21, 2009.

Received 14 Nov. 2008; and in revised form 9 Jan. 2009; accepted 11 Jan. 2009. instances fragments from differing exhibit collections were found to fit together. The multiplicity of species and exhibit collections as well as the small fragment sizes (most 1-3 cm) substantially increased the difficulty of the anthropological analysis. The fragments exhibited a variable level of burning termed "incomplete cremation" (1).

Individual human bone fragments were identified as to anatomic element and, if possible, laterality using reference collections. Identified fragments were then individually numbered and labeled. The forensic anthropology team coordinated the specimen transfers to specialists in other disciplines (in other states) for examination. Specimens were to be examined by consultants in several disciplines; for this reason, after checking with the DNA lab, we decided to package them in small plastic specimen bags. This provided protection for DNA-protocol handling, allowing specimens to be examined morphologically without contamination. Each bagged specimen was then placed in a similarly labeled box to provide protection for shipping. The various specimens were sorted into subsets to be sent for analysis by radiology, odontology, and mitochondrial DNA, or combinations. A detailed catalog database sheet accompanied the evidence transfer forms, along with a $\mathrm{CD}$ with the specimen photographs. In all, 33 boxed and labeled bones and fragments were sent for possible radiological identification by matching with any of the available antemortem radiographs.

Antemortem radiographs of the missing person/assumed decedent had been obtained and were made available to the forensic odontologist and radiologist. This included images of the dental arches, facial bones and lower half of the skull, the right shoulder, the lumbosacral spine, and the left hand and wrist.

When the specimens arrived for radiographic examination, each specimen was visually compared with the appropriate antemortem X-ray images. Promising fragments were painstakingly positioned to replicate the projection of that part on the antemortem study. As 
the victim had been young and healthy, there were no skeletal features of disease, degeneration, tumor, or trauma. Therefore, comparison was limited to the external configuration and internal trabecular pattern of each specimen. Most of the fragments were devoid of even these features when radiographed with fine detail using a mammography radiology unit and film.

\section{Results}

The anthropological examination produced a biological profile of a male with an estimated age at death in the early twenties, based on overall size of skeletal features and odontological analysis of a third molar root. Anthropological analysis of the fragmentary skeletal remains supported the age estimation, as evidenced by the adult size of bone and tooth elements, complete fusion of observed joint margins, changes to sternal rib ends, an absence of joint deterioration, and incipient fusion of cranial sutures. Stature and ancestry were indeterminate.

Intentional thermal alteration of these remains caused warping and shrinkage of several of the skeletal elements. The structural integrity of the burned bones was compromised not only by characteristic thermal fractures, warping, and scaling (2), but also by the perpetrator's intentional fragmentation, scattering, and commingling of the human remains with those of other species. Breakage and destruction of certain anatomical portions precluded some aspects of the anthropological analysis, such as the determination of ancestry, the estimation of stature, and complete trauma analysis (3). Our team was nonetheless able to identify enough elements to conclude that the remains were consistent with those of a single individual, as determined by the size, robusticity, elemental representation, and overall volume of skeletal material. From these fragments, we were also able to determine the sex and approximate age of the individual. There was no evidence of pathology or perimortem trauma.

We were able to partially reconstruct several skeletal elements from the dispersed fragments. However, the adjoined fragment margins generally did not have good continuity of their trabecular patterns because of the loss or breakage of delicate internal structures, mainly because of fire damage. The skeletal elements that we were ultimately able to match radiographically were mostly intact. Although these bones exhibited some heat-induced shrinkage, their general morphology was not distorted, and dimensional changes were proportional and sufficiently uniform to preserve the external configuration and internal trabecular pattern.

The anthropology team had selected the least-burned fragments of bone and teeth, which were carefully packed to prevent DNA contamination. These were sent for mitochondrial DNA testing. Too much of the organic material necessary to produce a signal had been lost through incineration. No DNA match was possible.

The odontologist found the dental remains to be consistent with the presumed victim's age and with the antemortem radiographs of the dental arches, facial bones, and lower half of the skull. However, the burned tooth and alveolar remnants were too fragmentary to produce a positive identification using the dental radiographs. Almost none of the tooth crowns or crown fragments were present due possibly to intentional removal by the perpetrator.

Antemortem radiographs of the right shoulder, the lumbosacral spine, and the left hand and wrist were sent along with 33 boxed and labeled bone fragments for radiological evaluation. Each specimen was visually compared with the antemortem images.
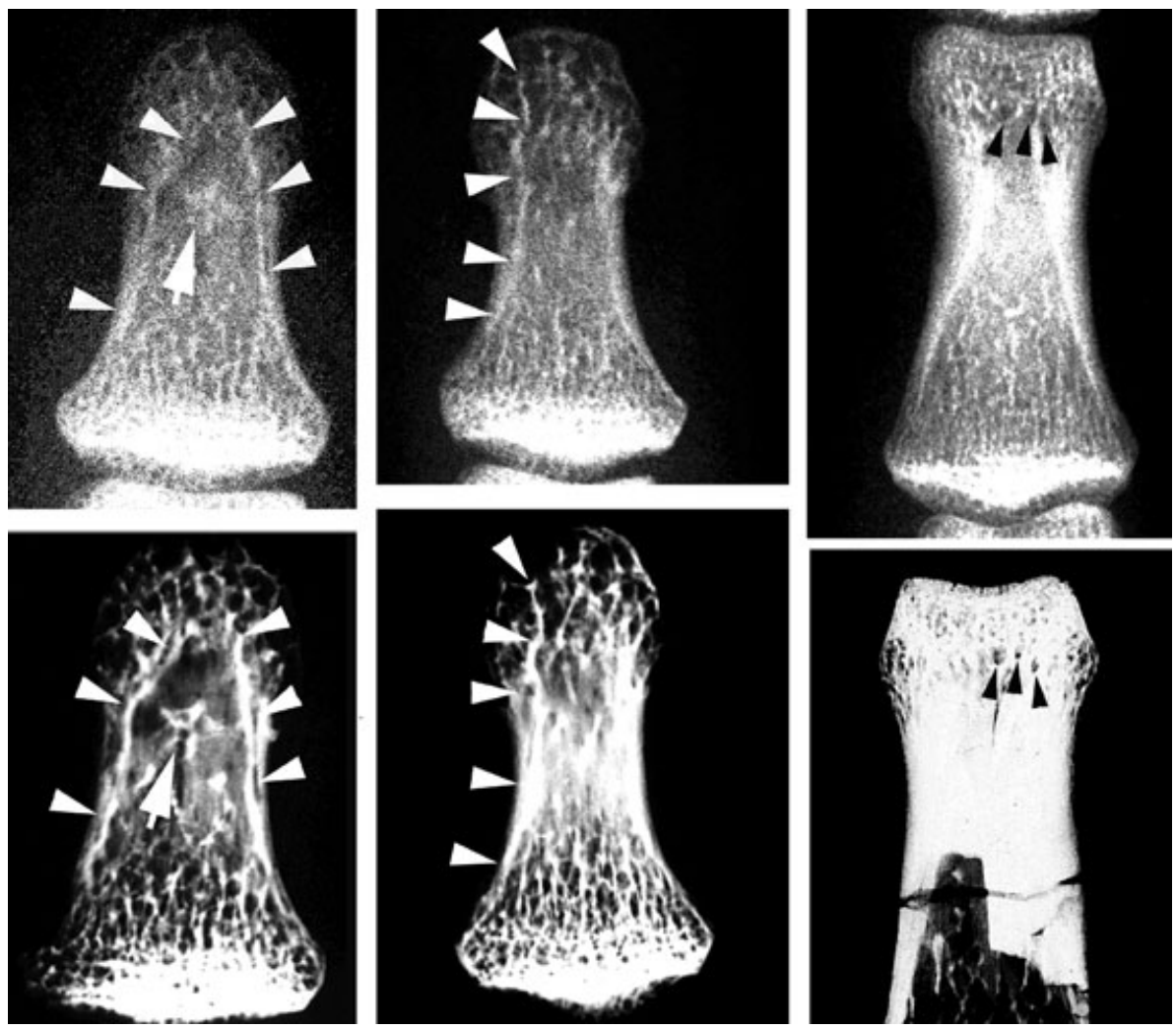

FIG. 1-Upper row: enlargements of portions of the antemortem radiograph of the victim's left hand. Lower row: postmortem radiographs of burned bones

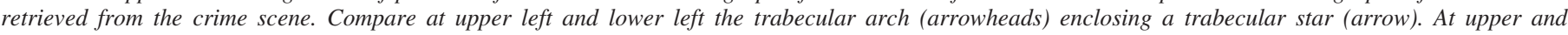

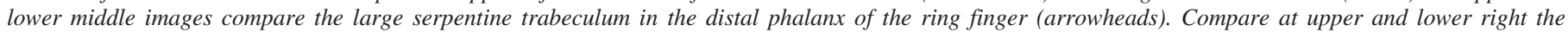
three round "owl eyes" in the distal end of the middle phalanx of the index finger. These matching patterns are unique and specific to a single individual. 
Promising fragments were painstakingly positioned to replicate the projection of that part on the antemortem study. As the victim had been young and healthy, there were no skeletal features of disease, degeneration, tumor, or trauma. Therefore, comparison was limited to the external configuration and internal trabecular pattern of each specimen. Most of the fragments were devoid of even these features when radiographed with fine detail using a mammography Xray unit and film.

After multiple repositioning and re-examination of fragments radiographically, positive matches were found in unique trabecular patterns in the terminal phalanges of the index and ring fingers and a partial fragment of the middle phalanx of the index finger from the left hand (Fig. 1).

Thus, the victim was positively identified with absolute medical certainty and sworn to upon discovery deposition. This identification was confirmed when, shortly before trial, the defendant stipulated to the murder and to the identity of the victim and a plea of insanity was entered. A jury found her sane and, hence, guilty of first-degree murder.

\section{Discussion}

It has long been recognized that distinctive radiographic features can be found in the bones of the hand (4). Almost half a century ago, Greulich (5) studied radiographs of the hands and wrists of 70 pairs of same-sexed twins, of which 40 pairs were believed identical, and found that all had individual distinguishing features. Trabeculation has, of course, provided positive identification through comparison of antemortem and postmortem radiographs of many other individual bones (6). Kahana and Hiss (7) reported identification of an unknown through a system of matching the bony trabecular pattern in a single phalanx of a thumb using computerized densotometric line maps or densitographs. The densitometer measures the varying densities encountered when scanning across the radiograph of a bone. The result can be recorded on a 2-dimensional map or profile of hills (trabeculae) and valleys (interstices) replicating the pattern within the bone. Profiles thus acquired by scanning the same line across antemortem and postmortem images can be used for comparison and matching. However, the trained or experienced observer usually can make accurate "eyeball" comparisons without resorting to such sophisticated instrumentation.

It is interesting that, in the second year after Roentgen's discovery, Walsh (8) produced X-ray images of a hand that had been impregnated with bismuth subnitrate showing knuckle folds, palmar lines, and fingerprint furrows. Apparently not knowing of this, Béclère $(9,10)$ in 1918 and 1920 published radiographic images of fingers lightly coated with lead tetroxide, thus producing fine fingerprints. Of course, the work of both men was quickly relegated to the category of historical curiosity with the widespread adoption of the cheap, quick, and easy ink print. The irony is that no one seemed to recognize that the terminal phalanges underlying those lead- or bismuth-lined cutaneous furrows had trabecular patterns just as distinctive.

This case demonstrates the advantage of interdisciplinary collaboration in solving forensic problems, emphasizes the usefulness of radiological evaluation of incinerated skeletal fragments when DNA extraction is impossible, and acknowledges the meticulous anthropological work and expertise essential to providing identifiable specimens for radiological study.

\section{References}

1. Correia PM. Fire modification of bone: a review of the literature. In: Haglund WD, Sorg MH, editors. Forensic taphonomy: the postmortem fate of human remains. Boca Raton, FL: CRC Press, 1997;275-98.

2. Symes SA, Rainwater CW, Chapman EN, Gipson DR, Piper AL. Patterned thermal destruction of human remains in a forensic setting. In: Schmidt CW, Symes SA, editors. The analysis of burned human remains. London: Academic Press, 2008;15-54.

3. Thompson TJU. Heat-induced dimensional changes in bone and their consequences for forensic anthropology. J Forensic Sci 2005;50:1008-15.

4. Koot MG, Saur NJ, Fenton TW. Radiographic human identification using bones of the hand: a validation study. J Forensic Sci 2005;50:263-8.

5. Greulich WW. Skeletal features visible on the hand and wrist which can be used for establishing individual identification. AJR Am J Roentgenol 1960;83:756-64.

6. Brogdon BG. Radiological identification of human remains. In: Brogdon BG, editor. Forensic radiology. Boca Raton, FL: CRC Press, 1998;149-87.

7. Kahana T, Hiss J. Positive identification by means of trabecular bone pattern comparison. J Forensic Sci 1994;39:1325-30.

8. Walsh D. Skin pictures by the X-rays. Br Med J 1897;1(1891):797.

9. Béclère H. La radiographe anthropométric du pouce (superimposition des empreites digitalis, du sequelette et de l'ongle). C R Acad Sci 1918;167:499-500.

10. Béclère H. La radiographe cutanée. J Radiol Electrol 1920;4:145-9.

Additional information-reprints not available from author:

B.G. Brogdon, M.D.

University Distinguished Professor Emeritus

Department of Radiology

University of South Alabama Medical Center

2451 Fillingim St., Mastin 301

Mobile, AL 36617

E-mail: gbrogdon@usouthal.edu 